Instructions for authors, subscriptions and further details:

http://brac.hipatiapress.com

\title{
La Subjetividad y la Fantasía en la Creación Plástica: Sus Procesos Psicológicos y Simbólicos en el Arte Infantil y Primitivo
}

Belén León Río ${ }^{1}$

1) Universidad de Sevilla. España

Date of publication: February $3^{\text {rd }}, 2015$

Edition period: February 2015 - June 2015

To cite this article: León Río, B. (2014). La Subjetividad y la Fantasía en la Creación Plástica: Sus Procesos Psicológicos y Simbólicos en el Arte Infantil y Primitivo. Barcelona, Research, Art, Creation, 3(1), 33-58. doi: 10.4471/ brac.2015.03

To link this article: http://dx.doi.org/10.4471/brac.2015.03

\section{PLEASE SCROLL DOWN FOR ARTICLE}

The terms and conditions of use, except where otherwise noted, are related to the Open Journal System and to Creative Commons Attribution License (CCBY). The indication must be expressly stated when necessary. 


\section{The Subjectivity and Fantasy in Artistic Psychological Creation: Its in Child and and Symbolic Primitive Art Processes}

Belén León Río

University of Sevilla

(Received: 6 May 2014; Accepted: 7 Desembre 2014; Published: 3 February 2015)

\section{Abstract}

Symbolism in art is largely connected with the structure of the unconscious, as children do in their artistic manifestations sometimes finding the same images and metaphors that have occurred in the art from older periods as prehistory this would lead us to believe that there is no single idea or concept that has no essential historical background, all based ultimately archetypal primitive forms, which are evident in the art through a consciousness that does not act only through thought but sees internally. In this article you will see how the unconscious would not be just a mere repository of the past, but is also full of germs of future psychic situations and creative ideas, the not few artist sometimes be their best work to the inspirations that appear suddenly unconscious, it would exert a great influence on the mythological, religious, artwork and all other cultural activities that the human being is expressed.

Keywords: Reason, intuition, unconscious, archetype, symbol, fantasy 


\section{LaSubjetividadylaFantasíaenla Creación Plástica: Sus Procesos Psicológicos y Simbólicos en el Arte Infantil y Primitivo}

Belén León Río

Universidad de Sevilla

(Recibido: 6 Mayo 2014; Aceptado: 7 Diciembre 2014; Publicado: 3 Febrero 2015)

\section{Resumen}

El simbolismo en el arte está conectado en gran medida con la estructura de lo inconsciente, al igual que hacen los niños en sus manifestaciones plásticas encontrándose a veces las mismas imágenes y metáforas que se han producido en el arte de otros periodos más antiguos como la prehistoria, esto nos llevaría a pensar que no existe una sola idea o concepción esencial que no posea antecedentes históricos, todas se basan en última instancia en formas primitivas arquetípicas, que se hacen patentes en el arte a través de una consciencia que no actúa sólo a través del pensamiento sino que percibe internamente.

En este artículo veremos como el inconsciente no sería sólo un mero depositario del pasado, sino que también está lleno de gérmenes de futuras situaciones psíquicas e ideas creativas, el artista no pocas veces, debe sus mejores obras a las inspiraciones que aparecen súbitamente del inconsciente, éste ejercería una gran influencia en el material mitológico, religioso, artístico y en todas las demás actividades culturales con las que se expresa el ser humano.

Palabras clave: Razón, intuición, inconsciente, arquetipo, símbolo, fantasía

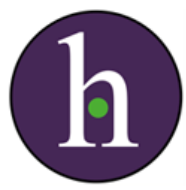




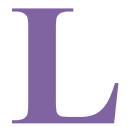

a mente inconsciente del hombre moderno conserva la capacidad de crear símbolos siendo el arte un canalizador de estos, ya que además de las formas que percibimos trasmiten mensajes que influyen en nuestra consciencia. De lo inconsciente surgirían efectos determinantes que aseguran en todo artista la similitud y aun la igualdad de la experiencia y de la creación imaginativa, lo que explicaría la coincidencia de muchas de estas imágenes arquetípicas a lo largo de la historia del arte y su identificación con el espectador que participaría igualmente de ellas. La creación artística es un campo de exploración idóneo de los productos de lo inconsciente, donde descubrimos a menudo estructuras arquetípicas o simbólicas que coinciden con temas míticos. Una de las pruebas fundamentales de esto es el paralelismo que podríamos calificar de universal, entre los temas mitológicos representados una y otra vez en la historia del arte. Esto no implica que la actividad artística pueda conocerse solamente por su fundamento arquetípico pero sí podemos tener en cuenta que dentro de ésta existen modelos arquetípicos que actúan con una dinámica de fondo que descifran el mensaje de ciertas tendencias evolutivas del inconsciente.

Esta forma de pensamiento funciona sin esfuerzo, espontáneamente y es dirigido por motivos inconscientes, se aparta de la realidad liberando tendencias subjetivas. El mito estaría emparentado con los productos del inconsciente y el artista en proceso de introversión encuentra muy a menudo en su obra reminiscencias del pasado individual además de numerosas huellas de estadios espirituales arcaicos. Como vemos el artista que se expresa simbólicamente, establece un enlace con los estratos más antiguos del espíritu humano, desde largo tiempo atrás sepultados por debajo del umbral de la consciencia, este mismo simbolismo se puede ver en las manifestaciones plásticas infantiles, detectándose desde que el niño empieza a dibujar sus primeros garabatos.

Mientras el individuo de hoy en día concentra toda su energía e interés en la ciencia y en la técnica, el hombre antiguo se consagraba a su mitología, encontramos aquí un mundo de fantasía que manaba de una fuente interna y que producía figuras plásticas o esquemáticas que concordaban con su esencia más profunda (revisar frase). C. G. Jung, llegó a la conclusión de que la época que creó los mitos pensaba de la misma manera que hoy lo hace el sueño. Incluso se descubren fácilmente en los niños rudimentos de mitos en formación y fantasías consideradas como reales. Bastaría con relajar el 
interés para eliminar la exacta adaptación psicológica al mundo real, que se expresa por medio del pensamiento dirigido y sustituirla por fantasías. Según este autor, nuestro cuerpo conserva en muchos órganos residuos de antiguas funciones y estados, así también, nuestro espíritu, aun cuando en apariencia ha superado aquellas arcaicas tendencias instintivas, lleva siempre la huella de la evolución recorrida y revive en los sueños, en la imaginación y a través del arte las épocas más distantes. De esta manera la mente humana tendría su propia historia y la psique conservaría muchos rastros de las anteriores etapas de su desarrollo, los contenidos del inconsciente ejercerían una influencia formativa sobre la psique. E. Pérez de Carrera describe como el arte tiene sus orígenes en el símbolo utilizando los sentidos hacia formas de consciencia que despierten emociones paralelas en la percepción de la obra plástica:

La escritura pictográfica tuvo mucho de simbólica. De pintar un caballo se pasó a metamorfosear con atributos equinos aquellos que habían demostrado cualidades especiales como la velocidad o la resistencia. Del caballo con cabeza humana se pasó a grabar un rostro o una característica como la huella de un casco o las ondas de las crines. Esta capacidad simbólica de llegar a sintetizar en un rasgo las características zoológicas, morfológicas o de fenómenos relacionados con la Naturaleza adquiere caracteres de un verdadero lenguaje con varios niveles paralelos de lectura, y quizá su principal cualidad sea que pueden ser percibidos más de un escalón de comprensión al mismo tiempo. La utilización de los sentidos hacia formas de consciencia que despiertan emociones paralelas es una de las fuentes de la poesía y el arte, y nace ligada al gráfico, al rasgo, al símbolo, al movimiento y a la necesidad mágica de vivir realidades ensoñadas.

De esta forma de compartir experiencias, de la que el arte de las cuevas $<$ prehistóricas $>$ es una referencia testimonial, quedan aún ejemplos en la escritura japonesa de sílabas y palabras que tienen su origen en el dibujo. El valor añadido de los idiomas ortográficos, de palabras que intentan contener un significado concreto, es la facilidad de intercambiar un pensamiento. El verso comulgado, la conversación, disminuyen en cierto modo la transmisión mistérico-mágica pero aumenta la comunicación ético-filosófica, proporcionando riqueza interior para enfocar la aventura individual del pensamiento. (2004, pp. 259 y 260) 
Sri Aurobindo ya menciona como las sociedades humanas en sus primeros comienzos o en fases primitivas solían tener una mentalidad marcadamente simbólica que impregnaba sus pensamientos, costumbres e instituciones. Este estadio de su desarrollo social era siempre religioso y activamente imaginativo en su religión, pues para este autor existe un parentesco natural entre simbolismo y el sentimiento generalizado, imaginativo o intuitivo, de modo que ambos van siempre a la par. De esta forma el símbolo expresaría algo que el hombre siente que está presente detrás de sí mismo, de su vida y de sus actividades: "el Divino, los dioses, el vasto y el profundo Inefable, una naturaleza de las cosas oculta, viva y misteriosa". (2002, p. 22)

El arquetipo sería la imagen de un contenido en su mayor parte trascendente a la consciencia. Un ejemplo de ello sería el símbolo mandala, cuya existencia a través de los milenios puede comprobarse en multitud de culturas y que en el arte aparece en todas las épocas, simboliza el fenómeno de la divinidad encarnada en el hombre. Estos arquetipos representan esencialmente un contenido inconsciente, que al ser percibido cambia de acuerdo con cada consciencia individual en que surge, de ahí las grandes diferencias en la representación artística de un mismo arquetipo en varios autores, incluso perteneciendo a una misma época. De lo inconsciente surgen así efectos determinantes que, independientemente de la transmisión, aseguran en el artista la similitud y aún la igualdad de la experiencia, expresándose en imágenes simbólicas surgidas a través de la creación que variarán de un artista a otro, en función de cada consciencia individual y transformándose en un mismo autor a lo largo de su evolución artística. En el arte vemos como estas representaciones no se heredan, sino en las formas que pueden variar infinitamente. La actividad creadora, estaría propulsada y regulada por estas "condiciones inconscientes colectivas" como las llamaría C. G. Jung, (1994, p. 148) produciendo configuraciones plásticas donde se repiten estructuras idénticas como por ejemplo la unificación de los contrarios en un tercero, la cuaternidad, el cuadrilátero, la cruz, la rotación, el círculo, la esfera, etc.

Estos arquetipos vivos formularían un fragmento inconsciente esencial y cuanto más universal sea la difusión de ese fragmento, tanto más universal será la acción del símbolo, pues roza en el artista y en el espectador la cuerda que le es afín; y siendo la más alta expresión posible de lo presentido y aún no sabido, incluyen en sí la atmósfera espiritual de su época, captando justo aquello que puede ser común a un gran grupo humano, produciendo en tales circunstancias una participación inconsciente. El arquetipo tendrá, por lo tanto, un lado que es accesible a la razón, pero también un lado, que es inaccesible 
a ésta, por cuanto está compuesto, no sólo, de datos de naturaleza racional, sino también, de los datos irracionales de la pura percepción interna y externa. La abundancia de presentimientos y significados del símbolo, hablan tanto al pensar, como al sentir, y su peculiar carácter de imagen cuando se configura en una forma sensorial artística, estimulan tanto la sensación como la intuición. El arte adquiere así un contenido que impresiona, influye y fascina, a través de una pre-forma inconsciente que parece pertenecer a la estructura heredada de la psique y puede a causa de ello, manifestarse como fenómeno espontáneo en el proceso artístico plástico, según C. G. Jung a través, del pensamiento fantaseador se establece un enlace con los estratos más antiguos del espíritu humano:

... toda buena idea y todo acto creador han brotado de la imaginación y han tenido su inicio en eso que pueda llamarse fantasía infantil. No sólo el artista, sino todo hombre creativo a de agradecer a la fantasía lo más grande que hay en su vida. El principio dinámico de la fantasía es lo lúdico, lo cual es también algo propio del niño; como tal, aparece asimismo incompatible con el principio del trabajo serio. Pero hasta ahora nunca ha nacido una obra creativa sin ese juego con la fantasía. Es incalculable lo que debemos a la fantasía. Por ello es miope tratar con desdén las fantasías en razón de su carácter aventurero o inadmisible. (1994, pp. 87 y 88 )

Autores y artistas se han interesado por el mundo simbólico artístico de los niños. Hegel decía del arte infantil:

Los intentos que hacen los niños de dibujar o modelar la figura humana dan como resultado meros símbolos, que sólo aluden a la forma viva que pretenden representar pero no son nada fieles a sus motivos y sus significados. En este aspecto, el arte es el principio puramente jeroglífico, no un signo fortuito o arbitrario sino una vaga representación del objeto para la mente. ${ }^{1}$

En Alemania el psiquiatra Hans Prinzhorn publicó en 1922 gran número de trabajos de pacientes mentales en su volumen Bildnerei der Geistes Kranken que provocaría una enorme conmoción entre los artistas y aficionados al arte donde señalaba: 


\section{BRAC - Barcelona Research Art Creation, 3(1)}

Sólo un tonto pensaría que lo que tiene de personal el sonido de un violinista se puede determinar midiendo las ondas sonoras y el registro armónico, o que el contenido expresivo de un Rembrandt de la última época se puede examinar mediante comparaciones con una tabla de colores.

Hacemos un compendio contrastando la esfera de los datos medibles con el reino de los datos expresivos, en el que los contenidos psíquicos aparecen inmediatamente y se captan sin la mediación de un aparato intelectual. Todos los movimientos expresivos sirven para este único fin: incorporar lo espiritual y así construir un puente desde el Yo al Tú [...] Encontramos las raíces de esto en circunstancias bien simples: con los niños, que en sus juegos inventan una animada danza o hacen garabatos, cuyo valor expresivo habla claramente al iniciado; o con los primitivos, que en sus máscaras de baile expresan de algún modo su visión del mundo, imbuida de ideas mágicas y demoniacas $[\ldots]{ }^{2}$

Nos encontraríamos aquí frente a un proceso psíquico que se desarrollaría preferentemente en lo inconsciente, donde la fantasía tendría que ver con el impulso lúdico o de juego, el artista plástico y todo hombre creativo deben mucho al principio dinámico de la fantasía, ya que, no hay que olvidar que lo más valioso del ser humano puede hallarse precisamente en su imaginación. El niño sacaría a la luz mediante ese juego con la fantasía lo que encerraría en su esencia más íntima, plasmándola en la materia plástica. En estos dominios de la fantasía, gran parte de sus contenidos pertenecen al inconsciente y la otra parte se encuentra en lo consciente, por lo que sólo a través de la imaginación, se establecería un enlace con nuestro pasado inconsciente, reviviendo en el arte las épocas más distantes.

\section{El Subjetivismo y la Fantasía en la Actividad Artística}

La fantasía creadora, dispondría no sólo de las fuentes personales del individuo, sino también del espíritu primitivo ya olvidado y sepultado por el tiempo. En el arte pueden aparecer como figuras abstractas que se expresan también en las mitologías de todos los pueblos y épocas. El conjunto de estas imágenes sería este inconsciente colectivo que todo ser humano heredaría en potencia. Estas imágenes surgirían de manera espontánea y coincidirían entre sí en todas las épocas y lugares del mundo. Mediante la fantasía nos apartaríamos de la 
realidad, liberando tendencias subjetivas las fantasías del artista manarían de una fuente interna, produciendo representaciones muy variadas.

El vínculo que tendría el espectador con la fantasía estaría condicionada principalmente por su relación con lo inconsciente en general, esta última relación se hallaría a su vez especialmente condicionada por el espíritu de la época de tal manera que si el grado de racionalismo predominante fuera alto el individuo se inclinaría menos a admitir lo inconsciente y sus productos, y viceversa. En el inconsciente, los elementos más heterogéneos se remplazarían los unos a los otros, de tal manera que todo aquello que en la consciencia estaría separado y es opuesto, confluiría en agrupaciones y configuraciones que, una vez llevadas a la luz de la consciencia, ya no aparecerían como contrarios. El psicólogo francés Théodule Ribot dice que la edad de oro del símbolo fue la época prehistórica:

Desde entonces ha sido arrollado por la presión hostil del pensamiento racional que, reforzado por la experiencia y por la razón misma, ha ido ganando terreno constantemente... La razón de ser del símbolo radica en la voluntad humana de expresar lo que es intrínsecamente inexpresable. ${ }^{3}$

La fantasía en su mayor parte es un producto de lo inconsciente, aunque también contiene partes conscientes. Sería esencialmente involuntaria, enfrentándose como algo extraño al contenido consciente. El material aflorado de la fantasía contendría imágenes del desarrollo psicológico del individuo en sus estados sucesivos, C. G. Jung lo compara con un trazado o una descripción del camino a seguir más tarde entre los opuestos. Según este autor, a pesar de que la consciencia a menudo no encontraría mucho que entender directamente en las imágenes, estas intuiciones contendrían sin embargo una "fuerza de vida" que puede causar un efecto determinante en la voluntad. Esta determinación de la voluntad se ejercería por ambos lados, por lo que pasado algún tiempo, los opuestos se volverían a fortalecer. Pero este renovado conflicto forzaría al individuo a recorrer otra vez el proceso, de tal manera que el individuo podría dar un paso más. Esta función mediadora de los opuestos fue llamada por C. G. Jung "función transcendente". Aquí la fantasía creativa tendría la función de unir los opuestos.

C. G. Jung decía que la infancia, gracias a su ingenuidad, proyecta una imagen más completa del ser humano, de todo el hombre en su individualidad 
auténtica, a consecuencia de ello la visión del niño y del primitivo despertaría en el hombre adulto anhelos que provienen de deseos y necesidades insatisfechos. Según este autor, estas partes correspondientes de la personalidad fueron retocadas en la persona a partir de la imagen de conjunto del hombre en beneficio de la adaptación:

El europeo, determinado en gran parte por su racionalidad, es mucho más ajeno a lo humano y de ello se envanece algo, sin darse cuenta de que ello se hace a costa de su intensidad de vida y que a causa de ello la parte primitiva de la personalidad es condenada a una vida existencia parcial subterránea. (1996, p. 251)

Paul Klee en 1912 comenta en su diario:

Porque éstos son los comienzos primitivos del arte, tal como se suelen encontrar en las colecciones etnográficas o en casa, en el cuarto de los niños. ¡No te rías lector! También los niños tienen capacidad artística, y hay sabiduría en que la tengan. Cuando más desvalidos son, más instructivos son los ejemplos que nos ofrecen; y se los debe mantener libres de corrupción desde que son muy pequeños. Las obras de los enfermos mentales nos ofrecen ejemplos paralelos; ni "conducta infantil" ni "locura" son aquí palabras insultantes, como suele serlo. Todo esto hay que tomarlo muy en serio. Más en serio que a todas las galerías públicas, cuando se trata de reformar el arte actual. ${ }^{4}$

En el niño de dos a seis años vemos como todo un simbolismo ya se manifiesta de forma muy activa en sus primeros dibujos donde mana todo un mundo interior intentando redescubrir su "Yo" más profundo al igual que hacía el hombre de la antigüedad. Según Sri Aurobindo, Bergson ya colocaba la intuición por encima del intelecto y la filosofía alemana reconoce la existencia de facultades suprarracionales y un orden de verdades suprarracionales. El proceso de génesis y producción de la obra plástica, estaría por tanto vinculada a la facultad creadora del ser humano, valorándose la fantasía y el genio como unos dones innatos en el individuo creativo. Toda obra, pone en juego tensiones entre sus elementos y para penetrar en ella, es necesario seguir las vicisitudes a través de las cuales la materia se subordina o impone a una forma que, a su vez, es portadora de significados. El niño desde los dos 
años en muchos casos ya desarrolla parte de estos símbolos en sus primeros dibujos. El inconsciente humano encierra todas las formas de vida y de funciones heredadas de la línea ancestral, de suerte que en cada ser humano nacido preexiste una disposición psíquica funcional adecuada, anterior a la consciencia haciéndose sentir su presencia y su actividad en la vida infantil a través de estos primeros grafismos.

August Macke en el manifiesto del expresionismo alemán llamado El Jinete Azul (Der Blaue Reiter) escribe:

Oír el trueno significa sentir su misterio. Entender el lenguaje de las formas significa estar más cerca de su misterio, vivir. ¿Acaso los niños no son creadores que crean directamente a partir del misterio de sus emociones, mucho más que los imitadores de las formas griegas? ¿Acaso los salvajes no son artistas que tienen sus propias formas, poderosas como el sonido del trueno, un trueno en el que cada flor y cada fuerza se expresa en forma $)^{5}$

La proyección fue una de las raíces del arte, siendo un recurso muy usado por los niños estudiados que suelen imaginar formas en las nubes, los troncos de árbol o las rocas sintiendo fascinación por estas manifestaciones de la naturaleza donde la mente infantil proyecta su imaginación. El artista prehistórico realizaría sus formas a partir de las sensaciones sugeridas por el entorno natural, siendo la materia un valor en sí misma así en Altamira un grupo de bisontes policromados del techo de las cavernas surgiría a partir de las formas naturales de la piedra que el artista contorneó para resaltar la figura. E. H. Gombrich señala como el arte rupestre no sería cualquier cosa menos primitivo, siendo un estilo ya muy desarrollado donde la proyección será una constante en la creación de arte:

Y sin embargo, la prioridad de la proyección pudo seguir determinando el carácter del estilo. A menudo hemos visto en qué grado el punto de partida del artista determina el producto final. El esquema sobre el que se basa una representación seguirá transparentándose a través de la elaboración última. Sería tentador suponer que el rasgo más notorio del arte de las cavernas, su falta de rigidez geométrica, puede relacionarse así como sus distantes raíces en formas indeterminadas, descubiertas y elaboradas por sucesivas generaciones. (1997, pp. 92-93) 
En el arte contemporáneo es muy usual resaltar las formas y texturas que ofrece la naturaleza, buscando la propia expresión natural. En escultura los artistas se dejan seducir por el grano y la textura de los materiales empleados, concediendo gran importancia a las características de la piedra o la madera, intentando extraer la natural esencia del medio. De esta manera siempre hubo artistas que han vislumbrado formas aprisionadas en la materia o en el propio paisaje, formas que ellos como artistas debían de esforzarse por liberar y presentar a la luz de la conciencia como ya ocurriera en el arte prehistórico, en el Renacimiento con Miguel Ángel hasta llegar al siglo XX, donde surge una nueva concepción del arte que no buscaba crear sobre la base de lo racional, sino emular las fuerzas germinales del entorno y adoptar las formas que le proporcionarán las formas erosivas de los elementos. Tal vez el origen del arte puede estar en estas similitudes que nos llevarían a la sombra proyectada por los objetos, animales y el propio hombre la silueta obscura sería el primer paso en la representación del mundo plástico. E. H. Gombrich decía: "Para el primitivo, el tronco de árbol que parece un animal puede convertirse en una suerte de animal." (1997, p. 90)

A finales de los años treinta, Bárbara Hepworth produjo algunas de sus esculturas más rigurosamente simplificadas, consistiendo varias de ellas en una columna aislada de mármol suavemente redondeada o delicadamente tallada para realzar su origen figurativo orgánico. Después de la segunda guerra mundial, realizó una serie de churingas o tótems, emparejados, que evocan los menhires neolíticos de Cornualles. Para el artista moderno, al igual que las sociedades antiguas y primitivas, las piedras sin labrar tenían un significado simbólico, ya que se creía con frecuencia que las piedras bastas y naturales eran moradas de espíritus o de dioses estos artistas intentaron extraer el alma de la piedra tallándola en función de la forma que ésta sugería. En muchos casos esta forma era una aproximación, más o menos definida a la figura humana como podemos apreciar en los antiguos menhires, los Hermes nacidos de las piedras de los linderos en la Antigua Grecia o los primitivos ídolos de piedra. Esta concepción primitiva de la fuerza mágica de la piedra está relacionada también con las piedras preciosas que en distinta épocas se les atribuyeron facultades mágicas y medicinales. El tema de la transmutación de la piedra aparece frecuentemente en las leyendas peruanas y colombianas y podría estar vinculado con el culto paleolítico de las piedras anímicas de los churingas al igual que ocurre con los menhires u hombres de piedra de la cultura megalítica que se extienden hasta el archipiélago del Pacífico. 
En Cornualles (Inglaterra) se ha encontrado dos grandes piedras circulares junto con unos monolitos neolíticos, ambas losas se hallaron puestas de pie. La más grande llamada tolven tiene un agujero de cuarenta y un centímetros de diámetro abierto en el centro, la más pequeña llamada Menetol se ha empleado supersticiosamente para curar niños enfermos haciéndolos pasar por la abertura. Tal vez Henry Moore se inspira en ellas para realizar algunas de sus obras que nos recuerdan la magia de esta época primitiva. El agujero sería símbolo de la abertura a lo desconocido, sería como la espera o la repentina revelación de una presencia. De un agujero abierto en el cráneo de Zeus por un hachazo asestado por Hefaistos, sale la diosa de la inteligencia, Atenea.

Este arquetipo estaría ligado a los símbolos de la fertilidad en el plano biológico, y de la espiritualización en el plano psicológico así en la India se interpreta el agujero como el órgano femenino por donde pasa el nacimiento al mundo y al mismo tiempo sería la puerta del mundo, por donde la muerte permite escapar a las leyes terrenas. El Pi chino, disco de jade que tiene un agujero circular en el centro, sería un símbolo del cielo. Henry Moore decía de esta expresión escultórica:

El primer agujero hecho en un trozo de piedra es una revelación.

El agujero conecta una parte con la otra, haciéndolo inmediatamente más tridimensional.

Un agujero puede tener en sí mismo tanto significado de contorno como una masa sólida. ${ }^{6}$

La materia seria transformada por el niño mediante un proceso que a veces puede resultar arbitrario y experimentado de acuerdo a ciertos presupuestos pálidos débiles e insuficientes, pero en el proceso, el niño al igual que el artista conecta con ideas primordiales que habitan en el interior del ser humano. Entre las figuras de bulto redondo realizadas en barro por los niños vemos numerosos ejemplos donde aparecen formas horadadas y perforadas por los mismos palillos de modelar en forma de círculo, sugiriendo la antigua forma de obtención del fuego mediante rotación. Existe una tendencia general a establecer un paralelismo entre la obtención de fuego mediante el barrenamiento y la sexualidad, poniendo el ejemplo del canto del Rigveda (III, 29, 1-3) que dice: "Es el madero giratorio; el procreador está pronto, trae a la dueña de la tribu. Hagamos girar a Agni a la antigua usanza." (C. G. Jung, 1995, p. 417) 
C. G. Jung (1990), señala como la importancia de la materia se manifiesta ante todo en la elección de la imagen de Dios en la piedra, esta elección aparece en la más antigua alquimia griega. La piedra se ha representado como lugar ocasional de nacimiento de los dioses como la piedra donde nace Mithra. La relación del lapis con la inmortalidad se establece desde épocas muy tempranas. Desde la prehistoria la piedra tiene espíritu. C. G. Jung dice de este arquetipo:

Es la panacea, la medicina catholica (la medicina universal), el alexipharmakon (antiveneno), la tintura que transmuta el metal en oro y el guijarro sin valor en piedra preciosa. Es lo que trae riqueza, poder y salud; como remedio del alma vence a la melancolía, y en un estadio superior, como un vivus lapis philosophicus, es un símbolo del Salvador, del anthropos y de la inmortalidad. Esta incorruptibilidad de la piedra se manifiesta también en la representación antigua, según la cual el cuerpo de los Santos se volvió como piedra. (1990, p. 45)

Desde muy pequeños los niños recogen de la naturaleza distintos tipos de piedras atraídos por sus texturas o color P. Teilhard de Chardin buscaba con seis o siete años alguna piedra, la más transparente o la mejor coloreada:

... cristales de cuarzo o de amatista y relucientes fragmentos sobre todo la calcedonia; lo que me era posible encontrar en la zona. En este último caso era, naturalmente, necesario que la sustancia preciada fuera resistente, inalterable iy dura!

Proceso imperceptible, pero que debía tener inmensa importancia en el curso de mi evolución espiritual, porque justamente gracias a la salida abierta a mis titubeos por la sustitución del Hierro por el Cuarzo en los vastos edificios del Planeta y de la Naturaleza, comencé, sin darme cuenta, a acceder verdaderamente al Mundo, hasta no poder gustar ya nada que no tuviera las dimensiones de lo Universal. (2002, p. 21)

Henry Moore se siente atraído por las formas de los guijarros erosionados que le sirven de inspiración:

Hay formas universales a las que todo el mundo está condicionado subconscientemente y a las que se puede reaccionar, si nuestro control consciente no las rechaza. 
Los guijarros muestran la forma en que la naturaleza trabaja la piedra. Algunos de los guijarros que recojo están atravesados por agujeros. Además de la forma humana me entusiasman tremendamente todas las formas naturales, como la formación de las nubes, los pájaros, los árboles y sus raíces y las montañas, que para mí son las arrugas de la superficie de la tierra, como pliegues. Es extraordinario como se parecen las ondas de la arena en la playa a las marcas de la gubia en el tallado de la madera.?

El arte de Henry Moore nunca es preconcebido o programado sino más bien el resultado de un proceso de conocimiento y experimentación graduales, sería como él mismo definiría "una expresión del significado de la vida, un estímulo al mayor esfuerzo de vivir." ${ }^{8}$. En otras aclaraciones suyas dice: "La observación de la naturaleza es parte de la vida de un artista, aumenta su conocimiento de las formas, le mantiene fresco y le protege de trabajar solamente con fórmulas y alimenta su inspiración." 9 El cuerpo humano, los animales, los huesos, las piedras, y las rocas son los modelos de Moore para la formación de un organismo plástico, para el "hacerse" de una escultura.

\section{EI Inconsciente y la Evolución de la Consciencia Respecto al Arte}

Los arquetipos existen y actúan en el arte, estas representaciones pueden variar muchísimo en detalle sin perder su modelo básico, siendo factores dinámicos que se manifiestan en impulsos teniendo su propia iniciativa y su energía específica que percibimos cuando experimentamos la peculiar fascinación que los acompaña, actúan como fuerzas creadoras que inspiran nuevas ideas. C. G. Jung decía que en el arte plástico ocurre lo mismo con la mano que maneja el lápiz de dibujo, el palillo de modelar o el pincel.

... lo que en última instancia decide es un oscuro impulso, un a priori empuja a configurar y no se sabe que la consciencia de otro es conducida por los mismos motivos; se tiene entonces el sentimiento de estar entregado a una contingencia subjetiva sin límites. Sobre todo el procedimiento parece flotar una presciencia, no sólo de la configuración sino también de su sentido. (1994, p. 148) 
Estas experiencias y consideraciones nos hicieron constatar que existen ciertas condiciones inconscientes colectivas que actúan como reguladores y propulsores de la actividad creadora de la fantasía y que, al poner al servicio de sus fines el material existente en la consciencia, producían las configuraciones correspondientes. Las artes plásticas alimentan el espíritu humano, integrando contenidos inconscientes que totalizan al hombre psíquico, produciendo consecuencias muy importantes como difíciles de describir. Ni siquiera C. G. Jung exponiendo este tipo de cuestiones respecto a la psicología pudo exponer adecuadamente las transformaciones que sufre el sujeto bajo la influencia del proceso que denominó "de individuación". Este suceso consistiría en hacer conscientes partes inconscientes de la personalidad, no produciéndose una simple asimilación de las mismas a la personalidad del yo ya existente, sino más bien se da una transformación de ésta. La afluencia de contenidos inconscientes vivifica y enriquece la personalidad, la voluntad como energía disponible, se subordina a la nueva estructura integrada, denominada por $\mathrm{C}$. G. Jung, "sí-mismo". La individuación significaría por lo tanto llegar a ser un ente singular, traduciéndose como la realización del sí-mismo o la realización de sí. La totalidad consciente es una afortunada unificación del yo y el símismo en la cual ambos mantienen sus características esenciales. El sí-mismo sólo tendría un sentido funcional cuando puede actuar como compensación de una consciencia del yo, si el yo se disolviera identificándose con el símismo surge como bien dice C. G. Jung una especie de "vago superhombre". El proceso de individuación sería el comienzo de un camino evolutivo, que debe tomar el ser humano, ya que, no excluye al mundo, sino que lo incluye, pues el sí-mismo abarca en sí infinitamente mucho más que un mero yo, tal como se puede apreciar en el simbolismo desde siempre.

C. G. Jung descubrió arquetipos del sí-mismo que también hemos hallado en el quehacer plástico del niño de dos a siete años, a través de técnicas como el dibujo sobre papel que permite la improvisación y el juego con la materia. Estas figuras incipientes contienen ya un rico material de fantasía, donde vemos un sinnúmero de complicadas configuraciones que se repiten y que coincidían con otras que C. G. Jung ya había estudiado con sus pacientes en el campo de la forma dramática, dialéctica, visual, acústica, de baile, pictórica, de dibujo o plástica, descubriendo mediante estos métodos el proceso inconsciente al que dio el nombre de proceso de individuación. Otro hecho coincidente en la configuración de estas manifestaciones artísticas fue la aparición de productos mitológicos, comprobándose que los niños de tales obras al igual que los pacientes de C. G. Jung tenían conocimientos de mitología que 
eran sobrepasados por sus creaciones de la fantasía configuradora. Lo que demostraría de modo inequívoco la coincidencia de las fantasías regidas por reguladores inconscientes con las manifestaciones de la actividad espiritual humana en general, conocidos por la tradición e investigación etnológica.

Sri Aurobindo nos habla de una sociedad que habiendo comenzado a espiritualizarse, haría de la revelación y la realización del Ser divino en el hombre el objetivo primordial de todas sus actividades, su educación, su conocimiento, su ciencia, su ética, su arte, su estructura económica y política:

En el arte, la sociedad espiritualizada no le asignaría como única misión la representación de imágenes del mundo objetivo y del mundo subjetivo, sino la de contemplar estos mundos con la visión significativa y creadora que traspasa las apariencias y revelan la Verdad y la Belleza, cuyas formas o apariencias, cuyos símbolos o imágenes significativas, son las cosas visibles e invisibles. (2002, p. 289)

C. G. Jung descubrió que esta simbología perteneciente a las más antiguas tradiciones sagradas que se repite en todas las culturas, estaría relacionada con los periodos de transición en la vida del individuo. Serían símbolos de transformación que están demandando la necesidad de liberarnos del estado actual en el que nos encontramos buscando en nuestra vida la transcendencia. Esta función de la consciencia sería la plena realización del potencial del símismo individual, los arquetipos señalarían el camino que debe buscar el hombre para su liberación para este autor el yo consciente estaría subordinado al sí-mismo que constituiría el centro de la personalidad psíquica total que sería ilimitada e indefinible, no susceptible de formulación y sólo simbólicamente expresable, constituyendo la totalidad del ser humano, tanto en lo consciente como en lo inconsciente. El sí-mismo se expresaría como una fuerza particular en cada hombre impulsándolo a la individuación y realización de su propia existencia. El sí-mismo trabajaría como una energía que apunta hacia una totalidad, donde el yo estaría subordinado al sí-mismo e iría más allá de sus valores e ideas, pudiendo incluso ir contra ellas, pues el sí-mismo enfrentaría al hombre constantemente a un camino de cambio y reevaluación. 


\section{Los Arquetipos Primitivos: Su Relación con la Actividad Plástica de los Niños y los Artistas del Siglo XX}

En el quehacer plástico de un niño se pueden ver a lo largo de su infancia, símbolos e imágenes que no permanecen estáticos, sino que cambian, evolucionan y gradualmente van desarrollando ciertos temas inconscientes o arquetipos. Hacia los dos años comienzan a dibujar sus primeros grafismos siendo siempre formas circulares que abarcan todo el papel, o conjuntos de círculos. El trazo gestual será muy importante en los niños al igual que hicieron los prehistóricos mediante líneas de expresión el artista conecta con su interior, Hans Arp apuntaba sobre esta forma de trabajar:

Entonces, con los párpados entornados, el movimiento interior fluye inmaculado hasta la mano. En una habitación oscura es aún más fácil seguir la guía del movimiento interior que al aire libre. Un director de música interior, el gran diseñador de las imágenes prehistóricas, trabajaba con la mirada vuelta hacia dentro. Así sus dibujos ganan en transparencia; se abren a la interpretación, a la inspiración repentina, a la recuperación de la melodía interior, a la aproximación circular, y la totalidad se transmuta en una gran exhalación. ${ }^{10}$

El empleo de formas sin relación directa, con ningún objeto real será una forma de expresión importante en los artistas del siglo XX aquí los niños también tienen una tendencia hacia los símbolos abstractos, estos símbolos pueden ir acompañados de objetos transformados como hicieran en su obra Klee, Kandinsky o Miró entre otros, siendo estos artistas los primeros que buscaron esta libertad primitiva en sus obras, tal vez por ello nos recuerde al arte infantil en sus primeras etapas. En sus obras no hay arriba ni abajo, como tampoco existe distinción o separación clara entre un objeto y otro. Los niños, como estos creadores, hacen un empleo continuo de la superposición sin normas de escala o proporción de tamaños (Fig. 1), representando a menudo gran variedad de símbolos como ya hiciera el hombre prehistórico. Así en los dibujos infantiles en sus primeros inicios, en torno a los dos o tres años, se caracterizaran por la ausencia de fondo, al igual que la concepción prehistórica del espacio, donde todas las direcciones lineales poseen igual derecho, cualquier inclinación respecto a la horizontal es permisible en los 360 grados. (Fig. 2) 

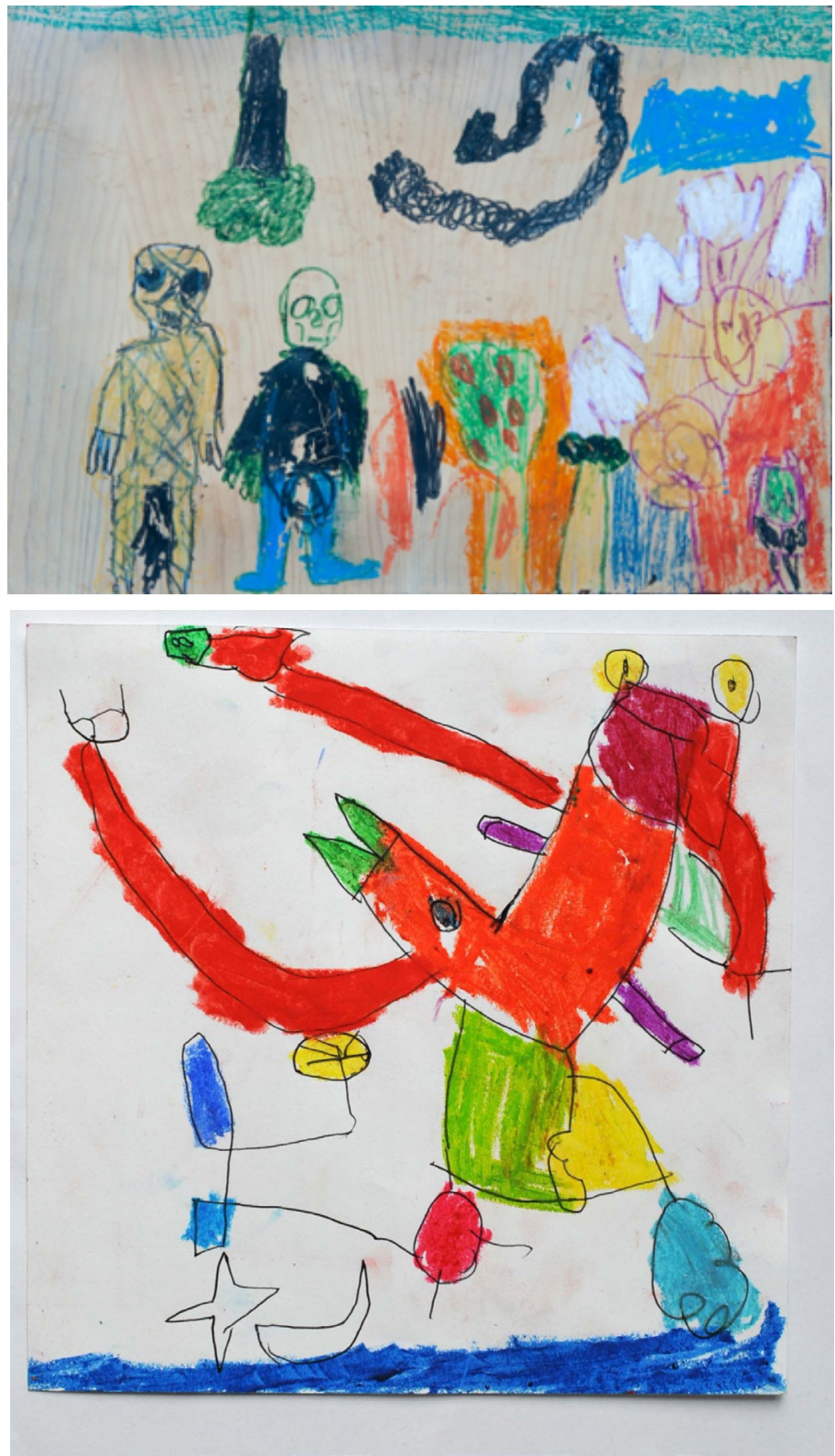

Figura 1. Dibujo niño de 7 años. (C)

Figura 2. Dibujo de niño de 4 años. (C) 
En estos primeros grafismos infantiles hemos encontrado paralelismos con la simbología del arte prehistórico así en el arte primevo naturalista del período

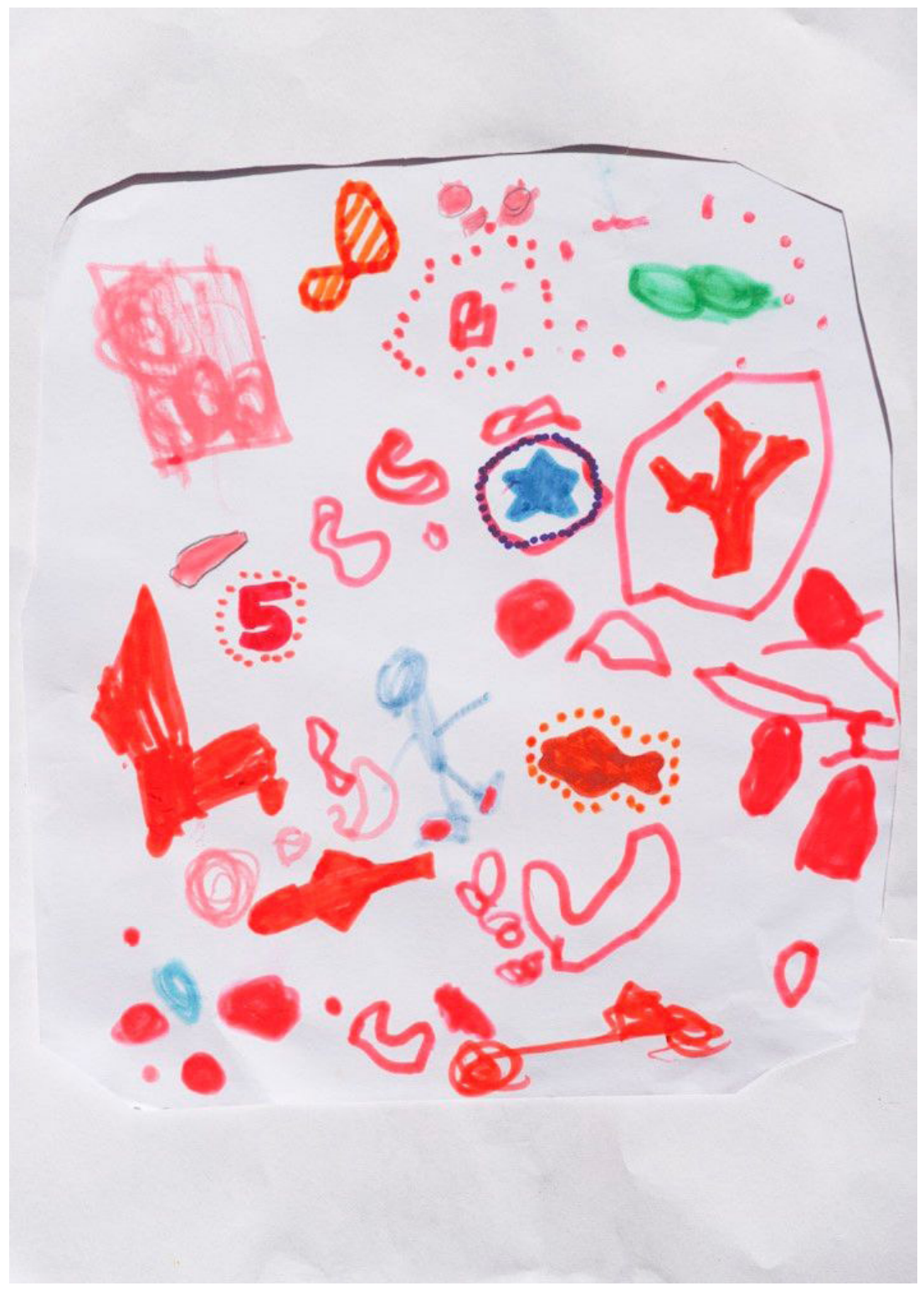

Figura 3. Dibujo niño de 7 años. (C) 
magdaleniense, el tipo más usual de abstracción sería aquel que concentra y simplifica la forma natural; y en un segundo lugar aquel que emplea formas (Foms and Shapes) inexistentes en la naturaleza y a las que se ha dotado de un significado simbólico conocido solamente por los iniciados. Mientras que un tercer tipo consistiría en mezclar temas naturales transformados con símbolos abstractos. En un cuarto tipo la concentración y simplificación se lleva tan lejos que los rasgos naturalistas se pierden por completo, en el periodo auriñaciense se encontrarán ejemplos de este tipo de abstracción, siendo en las últimas fases de la Edad del Bronce y los comienzos de la del Hierro cuando se llega a su total representación. Este último tipo de abstracción según S. Giedion, también se dará en el arte de la década comprendida entre 1910 a 1920 muchos artistas eliminaran el detalle, dando más fuerza a su obra. Los niños usarán este recurso de forma permanente en sus primeros dibujos incipientes realizados a los dos años, hasta la formación de símbolos más concretos a los seis y siete años. (Fig. 3)

En estas primeras etapas de la vida el niño representará con mucha frecuencia los arquetipos relacionados con el tema de la madre y la fecundidad que son también muy recurrentes en el mundo del arte. Para C. G. Jung el "anima" sería la madre que tendría dos aspectos, uno constructivo y otro destructivo la madre, es por un lado la seguridad, el alimento, el amor y el cobijo frente a una madre devoradora y castradora. Esta ambivalencia se correspondería con el mar y la tierra, en el sentido de que una y otra son receptáculos y matrices de la vida. El mar y la tierra son símbolos del cuerpo maternal. Nacer es salir del vientre de la madre, morir es retornar a la tierra. La madre es el abrigo, el calor y la ternura, siendo también por el contrario, el riesgo de opresión debido a la estrechez del medio y al ahogo por una prolongación excesiva de la función nodriza y de guía. Las grandes diosas madres han sido diosas de la fertilidad como Gea, Rea, Hera, Deméter para los griegos, Isis entre los egipcios y en las religiones helenísticas, Ishtar entre los asirobabilonios, Astarté para los fenicios e íberos y Kali entre los hindúes.

Los niños dibujan el arquetipo del hijo formándose en el útero de la madre mediante el procedimiento que los antropólogos denominan "radiografía" al referirse al arte primitivo. Los artistas contemporáneos al igual que los niños representan una imagen simultánea del interior y el exterior al mismo tiempo, para ello muestran el objeto como si fuera trasparente, delineando el contorno y representando después el interior. (Fig. 4 y 5) 

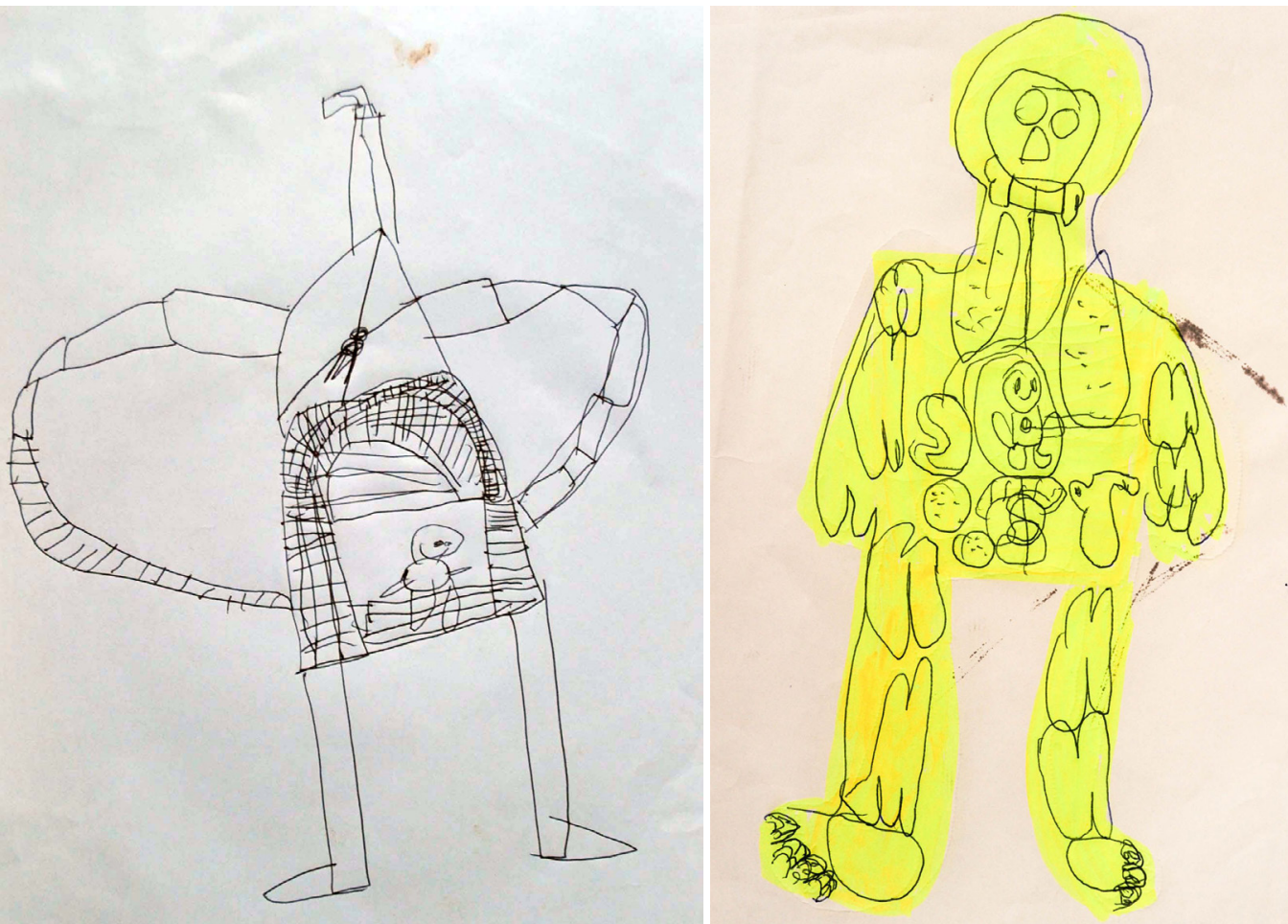

Figura 4. Hijo formándose en el útero de la madre, dibujado por un niño de 4 años.(C) Figura 5. Hijo formándose en el útero de la madre, dibujado por un niño de 5 años.(C)

El niño no reproduce a veces el objeto real que éste tiene ante sí, sino que lo interpreta al igual que los artistas contemporáneos, mostrando únicamente elementos invisibles de este objeto y al mismo tiempo es posible que otros que saltan a la vista sean enteramente desdeñados. El erudito francés G. H. Luquet en su obra L'art primitif (1930) compara metódicamente el significado de los dibujos infantiles, del arte primitivo y del arte prehistórico diciendo: "Para el hombre de hoy, una pintura es comparable cuando reproduce lo que sus ojos ven; para el hombre primitivo lo es cuando expresa lo que su mente sabe." 11 
Paul Klee, en su dibujo Getroffenes Muttertier (1923) usa este recurso de la trasparencia para representar un animal saeteado mientras sus crías hambrientas buscan sus ubres para alimentarse. Marc Chagall pintará este mismo tema de la madre, en Retrato de Vava de 1966, donde vemos una mujer con una abertura oval trasparente en su regazo que contiene una pareja de novios besándose como preludio de fecundidad.

La copa tiene que ver con el seno materno que produce la leche, en la India la copa de oblación del soma se asimila al creciente lunar, el soma sería el bálsamo de la inmortalidad. El grial medieval, sería otro arquetipo ligado a la copa, el cáliz de la última cena que recogió la sangre de Cristo, la búsqueda de éste simboliza la aventura espiritual, tiene que ver con dos talismanes de la religión céltica precristiana el caldero de Dagda y la copa de soberanía para C. G. Jung, simbolizaría la plenitud interior tan buscada por los hombres. E. Pérez de Carrera lo interpreta en este mismo sentido:

Puede que la sangre sagrada, el Grial que buscaban los caballeros de Arturo, no fuera la copa del Galileo crucificado en Jerusalén sino un misterioso estado de consciencia que proponía una búsqueda interior, y sólo los caballeros, las gentes que juraban lealtad, sacro-oficio, entrega, generosidad y defensa de los débiles podían pretender semejante hazaña. $(2004$, p. 85)

Las manos han sido representadas como símbolos mágicos en la prehistoria mediante impresiones en relieve sobre arcilla o imágenes directas de manos pintadas sobre la superficie parietal con ayuda de colores, en positivo o negativo. S. Giedion describe dos técnicas:

a) Impresión positiva: la mano se recubre de color rojo o negro y se aplasta contra la superficie pétrea, encontrándose en los repliegues de roca de las cavernas en color ocre, rojo y en manganeso azul-negro.

b) Impresión negativa: se coloca la mano contra la pared de piedra, y se extiende o se sopla el color alrededor de los contornos de los dedos y la planta.

En los niños se pude observar en edades muy tempranas la utilización de las dos técnicas descritas, se untan las manos con tempera y las plasman sobre el papel o bien colocan la palma de la mano sobre el papel contorneando luego con una línea la silueta de la mano. (Fig. 6) 


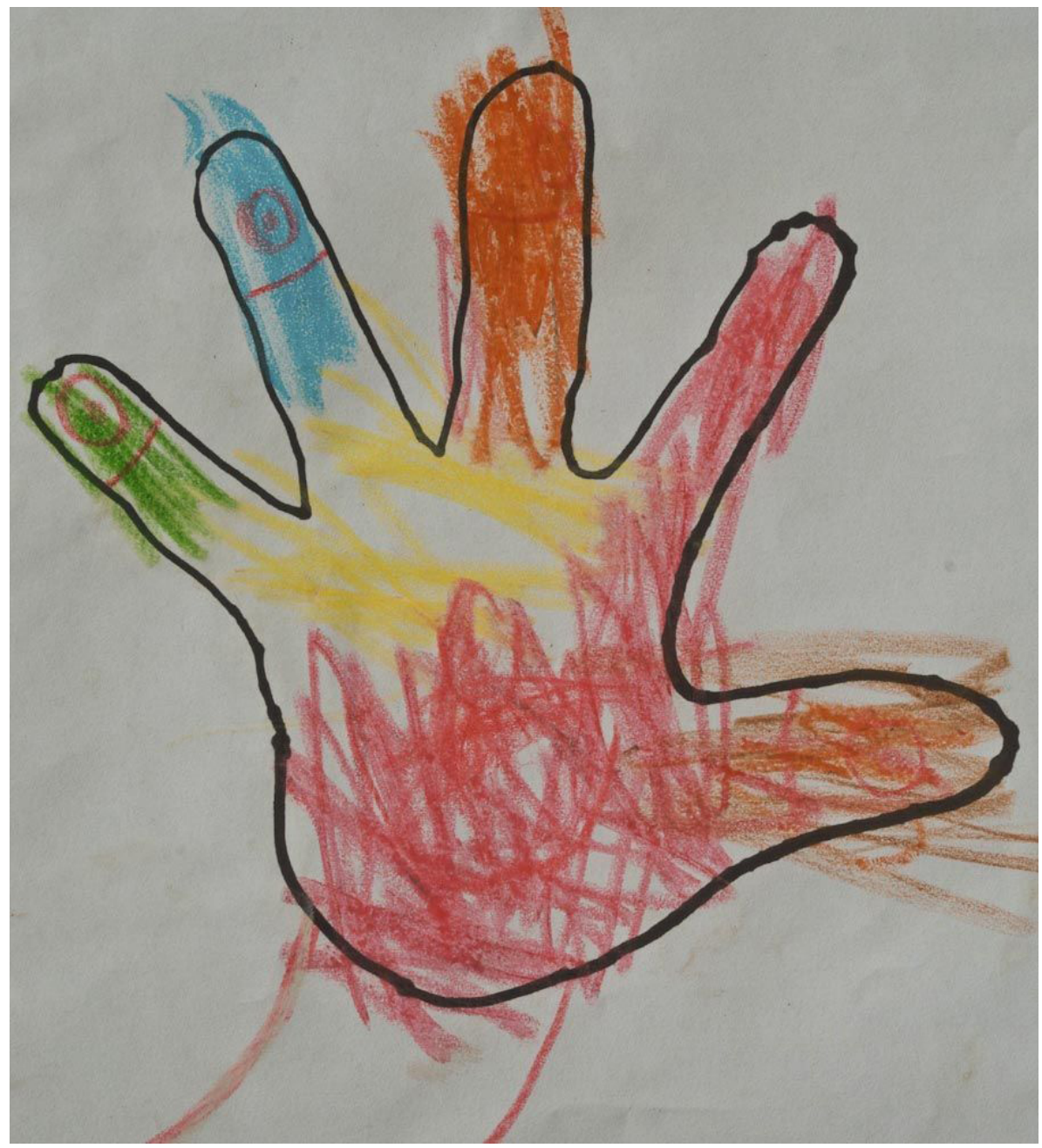

Figura 6. Palma de la mano sobre el papel contorneando la silueta. (Dibujo de un niño de 7 años). (C)

S. Giedion nos dice acerca de este símbolo: "En las culturas más dispares de las cuatro partes del mundo aparecen manos provistas de significado simbólico. Lo más que tienen en común es su afinidad humana: rara vez puede apreciarse otra vinculación directa con ellas.” (1991, p.122) 


\section{Conclusiones}

Toda esta simbología del niño tiene su importancia en su desarrollo, por lo que no debemos desdeñarla, nuestros métodos de enseñanza deben ser menos restrictivos, preocupándonos principalmente por estimular su creatividad y que trabaje sobre sus propias experiencias lúdicas y emocionales, donde busque temas de expresión con un alcance ilimitado.

Como vemos, el niño al nacer traería consigo un cerebro heredado de los antepasados que sería el resultado orgánico de la función psíquica de todos los ascendientes en el estarían preformados los instintos, todas las imágenes primordiales que han constituido siempre el fundamento del pensar humano y todo el tesoro de los temas mitológicos en toda su insospechada variedad, el niño produciría a veces combinaciones de ideas y símbolos, que no cabe atribuir a las experiencias de su existencia individual, sino más bien a la historia del espíritu humano.

El modo de pensamiento primitivo, analógico, del sueño y el mismo quehacer artístico recrean estas antiguas imágenes del inconsciente que aparentemente creemos están causadas por nuestra consciencia y sin embargo poseen su propia realidad y espontaneidad. La comprensión de esas imágenes, surgidas de lo más hondo de la psique es de vital importancia en la problemática del proceso del devenir de la personalidad del ser humano, siendo el arte una fuente importantísima en la aportación de símbolos.

\section{Notas}

${ }^{1}$ Autor citado por E. H. Gombrich, La preferencia por lo primitivo. Episodios de la historia del gusto y el arte de Occidente, Ed. Debate, Londres, 2002, p. 149.

2 Autor citado por E. H. Gombrich, La preferencia por lo primitivo. Episodios de la historia del gusto y el arte de Occidente, Ed. Debate, Londres, 2002, p. 264.

3 S. Giedion, El presente eterno: los comienzos del arte, Col. Alianza Forma $n^{\circ} 16$, Ed. Alianza Editorial, Madrid, 1991, p. 120.

${ }^{4}$ Autor citado por E. H. Gombrich, La preferencia por lo primitivo. Episodios de la historia del gusto y el arte de Occidente, Ed. Debate, Londres, 2002, p. 261.

5 Autor citado por E. H. Gombrich, La preferencia por lo primitivo. Episodios de la historia del gusto y el arte de Occidente, Ed. Debate, Londres, 2002, p. 224.

${ }^{6}$ Autor citado por D. Mitchinson. Henry Moore. Escultura, Ed. Polígrafa, Barcelona, 1981, p 46. 
${ }^{7}$ Autor citado por D. Mitchinson, ibídem, p. 26.

${ }^{8}$ Autor citado por D. Mitchinson, ibídem, p. 7

${ }^{9}$ Autor citado por D. Mitchinson, ibídem, p. 25.

${ }^{10}$ Autor citado por S. Giedion, ibídem, p. 81.

${ }^{11}$ Autor citado por S. Giedion, 1991, p. 74.

\section{Referencias}

Aurobindo, Sri. (2002). El ciclo humano. Barcelona: Fundación Centro Sri Aurobindo.

Giedion, S. (1991). El presente eterno: los comienzos del arte. Madrid: Col. Alianza Forma $\mathrm{n}^{\circ} 16$, Alianza Editorial.

Gombrich, E. H. (1997). Arte e ilusión. Estudio sobre la psicología de la representación pictórica. Madrid: Debate.

Gombrich, E. H. (2002), La preferencia por lo primitivo. Episodios de la historia del gusto y el arte de Occidente, Madrid: Debate.

Jung, C, G. (1990). Psicología y simbólica del arquetipo. Barcelona: Col.

Biblioteca de Psicología Profunda no 29, Paidós.

Jung, C. G. (1994). Arquetipos e inconsciente colectivo. Barcelona: Col.

Biblioteca de Psicología Profunda $n^{\circ}$ 14, Paidós.

Jung, C.G. (1995). Los complejos y el inconsciente. Madrid: Alianza.

Jung, C. G. (1996). Recuerdos, sueños, pensamientos. Barcelona: Col.

Biblioteca Breve, Seix Barral.

Mitchinson, D. (1981). Henry Moore. Escultura. Barcelona: Polígrafa.

Pérez de Carrera, E. (2004). 49 Respuestas a la aventura del pensamiento, tomo I. Madrid: Fundación Argos.

Teilhard de Chardin, P. (2002). El corazón de la materia. Santander: Col. "El pozo de Siquen"139, Sal Terrae. 
Belén León Río: Profesora Titular Interina del Departamento de Escultura e História de las Artes Plásticas. Universidad de Sevilla.

Contact Address: Facultad de Bellas Artes. C/Laraña n³, CP 41003, Sevilla.

E-mail address: belenleon@us.es 